\title{
Sensibilidade de Cultivares de Cana-de-Açúcar à Mistura TRIFLOXYSULFURON-SODIUM + AMETRYN ${ }^{1}$
}

\author{
Sensitivity of Sugarcane Cultivars to Trifloxysulfuron Sodium + Ametryn Mixture \\ FERREIRA, E.A. ${ }^{2}$, SANTOS, J.B. ${ }^{3}$, SILVA, A.A. ${ }^{4}$, VENTRELLA, M.C. ${ }^{5}$, BARBOSA, M.H.P. ${ }^{4}$, \\ PROCÓPIO, S.O. ${ }^{6}$ e REBELLO, V.P.A. ${ }^{7}$
}

\begin{abstract}
RESUMO - O trabalho constou de dois ensaios e teve como objetivo avaliar a sensibilidade de 11 cultivares (SP80-1842, SP79-1011, SP81-3250, SP80-1816, RB855113, RB835486, RB845210, RB867515, RB928064, RB72454 e RB855536) e quatro clones (RB947643, RB855002, RB957712 e RB957689) de cana-de-açúcar à mistura pré-formulada dos herbicidas trifloxysulfuron-sodium $\left(18,5 \mathrm{~g} \mathrm{~kg}^{-1}\right)+\operatorname{ametryn}\left(731,5 \mathrm{~g} \mathrm{~kg}^{-1}\right)$, denominada Krismat $\circledast$. Os cultivares e os clones foram cultivados em vasos em ambiente não-protegido. Em ambos os ensaios a mistura herbicida foi aplicada aos 60 dias após a brotação (DAB). No ensaio 1, a mistura herbicida foi aplicada em dose única de $2,00 \mathrm{~kg} \mathrm{ha}^{-1}$ sobre todos os cultivares e clones, enquanto no ensaio 2 a mistura foi aplicada nas doses de 1,00, 2,00 e 6,00 kg ha-1 sobre os cultivares RB855113 e RB867515. Após a aplicação do herbicida e aos 45 dias após a aplicação dos tratamentos (DAT), por ocasião da colheita, foram feitas avaliações semanais de fitotoxicidade, avaliando-se também a biomassa seca da parte aérea dos 11 cultivares e dos quatro clones. As variáveis altura da planta, número de folhas, área foliar e biomassa seca da parte aérea e do caule foram avaliadas no segundo ensaio. O cultivar RB855113 apresentou alta sensibilidade à mistura herbicida; os genótipos SP80-1842, SP80-1816, SP79-1011 e RB957689 apresentaram sensibilidade média; e os demais mostraram boa tolerância a esse produto. Para o cultivar RB855113, o maior índice de toxidez foi observado no período de 20 a 27 DAT. Nesse periodo observou-se redução da altura da planta, do número de folhas, da área foliar e da biomassa seca da parte aérea e do caule com o aumento das doses do produto. O cultivar RB867515 apresentou-se tolerante às menores doses do herbicida, porém, na maior dose testada, ele se mostrou sensivel, observando-se redução nas características avaliadas.
\end{abstract}

Palavras-chave: herbicidas, tolerância, seletividade.

ABSTRACT - The objective of this study was to evaluate the sensitivity of 11 cultivars (SP80-1842, SP79-1011, SP81-3250, SP80-1816, RB855113, RB835486, RB845210, RB867515, RB928064, $R B 72454$ and $R B 855536)$ and four clones (RB947643, RB855002, RB957712 and RB957689) of sugarcane to the pre-formulated mixture of the herbicides trifloxysulfuron-sodium $\left(18.5 \mathrm{~g} \mathrm{~kg}^{-1}\right)+$

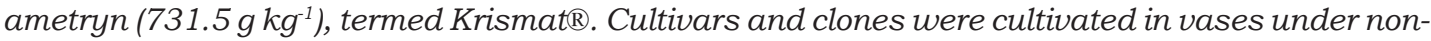
protected environment. In both assays, the herbicide mixture was applied at 60 days after sprouting. In assay 1, the herbicide mixture was applied at a single rate of $2.00 \mathrm{~kg} \mathrm{ha}^{-1}$ on all the cultivars and clones, while in assay 2 it was applied at rates of 1.00; 2.00 ; and $6.00 \mathrm{~kg} \mathrm{ha}^{-1}$ on cultivars RB855113 and RB867515. After herbicide application and harvest at 45 days after treatment (DAT), weekly evaluations of phytotoxicity (\%), and dry matter were conducted as well. The variables plant height, leaf number, leaf area and dry matter of the aerial part and stalk were evaluated only in the second assay. RB855113 cultivar showed the highest sensitivity to the herbicide mixture; the genotypes SP80-1842, SP80-1816, SP79-1011 and RB957689 showed medium sensitivity

Recebido para publicação em 13.9.2004 e na forma revisada em 21.4.2005.

2 Mestrando do Departamento de Biologia Vegetal, Universidade Federal de Viçosa - UFV, 36570-000 Viçosa-MG, $<$ evanderalves@yahoo.com.br>. ${ }^{3}$ Doutorando do Departamento de Fitotecnia - UFV; ${ }^{4}$ Professor do Departamento de Fitotecnia - UFV; ${ }^{5}$ Professor do Departamento de Biologia Vegetal - UFV. ${ }^{6}$ Universidade de Rio Verde - Faculdade de Agronomia, Campus Universitário, 75901-970 Rio Verde-GO. ${ }^{7}$ Acadêmico de Agronomia - UFV. 
and the clones presented good tolerance. For the RB855113 cultivar, the highest toxicity index was observed from 20 to 27 DAT. Reduction of plant height, leaf number, foliar area and dry matter of the aerial part and stalk was observed during this period due to the increase of the product doses. Cultivar RB867515 was tolerant at the lowest herbicide doses. However, it was found to be sensitive, at the highest tested dose.

Key words: herbicides, tolerance, selectivity.

\section{INTRODUÇÃO}

Apesar de a cana-de-açúcar ser altamente eficiente na utilização dos recursos disponíveis para o seu crescimento e de apresentar fisiologia do tipo $\mathrm{C}_{4}$, ela é muito afetada pela competição com as plantas daninhas, por apresentar, na maioria das situações, brotação e crescimento inicial lentos (Procópio et al., 2003). Em conseqüência dessa característica, é necessário manter a lavoura de cana-deaçúcar livre de plantas daninhas no periodo inicial, que varia de 60 a 90 dias (Procópio et al., 2003). Por ser tal cultura cultivada em grandes áreas, uma das ferramentas mais utilizadas para o manejo das plantas daninhas consiste na aplicação de herbicidas.

Diferentes cultivares de cana-de-açúcar têm apresentado respostas diferenciadas aos herbicidas, tendo como conseqüências freqüentes problemas de fitotoxicidade, chegando a ocasionar redução na produtividade do canavial. O comportamento diferenciado de genótipos de cana-de-açúcar diante de diversos herbicidas (Constantinin, 1997; Veline et al., 2000; Procópio et al., 2003), associado ao estádio de desenvolvimento desta cultura (Wixson et al., 1991), tem sido fator importante na tolerância de cultivares a herbicidas.

A seletividade a herbicidas não pode ser determinada apenas pela verificação ou não de sintomas de intoxicação, pois já são conhecidos exemplos de produtos que podem reduzir a produtividade das culturas sem causar efeitos visualmente detectáveis e, também, outros que provocam injúrias acentuadas, mas que permitem a recuperação plena da cultura (Silva et al., 2003). Dessa forma, quando o objetivo for avaliar os efeitos de herbicidas sobre a cana-de-açúcar, é fundamental que, além de avaliar as injúrias provocadas por eles, seja incluída também a taxa de crescimento e a produtividade da cultura (Veline et al., 2000).
O herbicida trifloxysulfuron-sodium, apesar de causar fitotoxicidade diferenciada a cultivares de cana-de-açúcar, é recomendado para essa cultura e está sendo amplamente utilizado em pós-emergência inicial (Procópio et al., 2003). A boa aceitação desse produto pode ser atribuída ao amplo espectro de ação, ao uso em baixas doses e ao longo efeito residual no solo, garantindo o controle de plantas daninhas durante o desenvolvimento inicial da cultura (Santos et al., 2004).

O trifloxysulfuron-sodium é comercializado para o uso na cana-de-açúcar em mistura com ametryn, formando o produto comercial Krismat ${ }^{\circledR}$. O ametryn apresenta fácil absorção pelo sistema radicular e pelas folhas; seus sintomas de intoxicação em cana-de-açúcar se caracterizam por clorose seguida de necrose, iniciando-se pelos bordos das folhas (Velini et al., 2000). Quando utilizado em pósemergência, os sintomas de intoxicação na cana-de-açúcar podem se apresentar de forma restrita ou ser mais acentuados nos pontos de contato da calda herbicida com as folhas (Procópio et al., 2003). A eficiência de misturas do trifloxysulfuron-sodium com ametryn e com MSMA no controle de espécies de plantas daninhas em lavoura de cana-de-açúcar foi avaliada por Schumm \& Braz (2002), os quais constataram que todas essas misturas foram eficientes no controle dessas plantas, causando apenas moderada intoxicação à cana-de-açúcar.

Neste trabalho, avaliou-se a sensibilidade dos cultivares SP80-1842, SP791011, SP81-3250, SP80-1816, RB855113, RB835486, RB845210, RB867515, RB928064, RB72454 e RB855536 e dos clones RB947643, RB855002, RB957712 e RB957689 ao Krismat $®$ (mistura comercial dos herbicidas trifloxysulfuron-sodium + ametryn), visando melhor posicionamento dessa mistura no campo. 


\section{MATERIAL E MÉTODOS}

Foram realizados dois ensaios na Unidade de Crescimento de Plantas (UCP) do Departamento de Biologia Vegetal da Universidade Federal de Viçosa, em ambiente não-protegido. Os experimentos foram conduzidos em vasos contendo seis litros de substrato composto de Argissolo Vermelho-Amarelo adubado, conforme recomendado para a cultura da cana-de-açúcar (CFSEMG, 1999).

No primeiro experimento foram avaliados 11 cultivares de cana-de-açúcar (SP80-1842, SP79-1011, SP81-3250, SP80-1816, RB855113, RB835486, RB845210, RB867515, RB928064, RB72454 e RB855536) e quatro clones (RB947643, RB855002, RB957712 e RB957689), sendo plantados três toletes com uma gema em cada vaso. Aos 60 dias após a brotação (DAB), fez-se a aplicação do herbicida Krismat ${ }^{\circledR}$ [trifloxysulfuron-sodium $\left(18,5 \mathrm{~g} \mathrm{~kg}^{-1}\right)+$ ametryn $\left.\left(731,5 \mathrm{~g} \mathrm{~kg}^{-1}\right)\right]$ nas doses de 0,00 e $2,00 \mathrm{~kg} \mathrm{ha}^{-1}$, totalizando 30 tratamentos, dispostos em blocos casualizados, com três repetições.

Neste experimento, as características avaliadas foram a porcentagem de fitotoxicidade aos 6, 13, 20, 27, 34 e 41 dias após aplicação dos tratamentos (DAT) e o acúmulo de biomassa seca da parte aérea, determinada por ocasião da colheita do ensaio, aos 45 DAT. Na avaliação de fitotoxicidade foram atribuídas notas variando de zero a $100 \%$, sendo zero correspondente à ausência de toxidez e 100\% à morte total da planta. Os sintomas foram registrados por câmera digital.

No segundo experimento, foram aplicadas, aos 60 dias após a brotação das gemas (DAB), quatro doses da mistura herbicida $(0,00 ; 1,00$; 2,00 ; e $6,00 \mathrm{~kg} \mathrm{ha}^{-1}$, correspondendo, respectivamente, a zero, metade, uma vez e três vezes a dose recomendada) sobre dois cultivares de cana-de-açúcar (RB855113 e RB867515), totalizando oito tratamentos, dispostos em blocos casualizados, com três repetições.

Neste ensaio, além da avaliação de intoxicação da cana-de-açúcar pelo herbicida (\% de fitotoxicidade), realizada aos $6,13,20,27,34$ e 41 DAT, no momento da colheita (45 DAT) foram avaliados a altura de plantas, a área foliar, o número de folhas e as biomassas secas foliar e caulinar.
Na interpretação dos resultados, os dados referentes a altura de planta, número de folhas, área foliar e biomassas foliar e caulinar, tanto no primeiro quanto no segundo experimento, foram transformados em porcentagem relativa à média da testemunha.

Quanto aos dados relativos à evolução da fitotoxicidade no tempo referente ao primeiro ensaio, eles foram interpretados utilizando-se a análise de regressão com significância de $1 \%$ pelo teste $\mathrm{F}$. Além disso, as médias dos cultivares referentes a fitotoxicidade aos $14 \mathrm{e}$ 34 DAT e quantificação da biomassa seca foram agrupadas segundo o critério de Scott Knott a $5 \%$ de probabilidade. No segundo experimento, todas as características foram avaliadas por regressão com significância de 1 ou $5 \%$ pelo teste $F$, para interpretação dos resultados.

Os cultivares que apresentaram índice de intoxicação (\% de fitotoxicidade) superior a $27 \%$, associado à elevada redução no acúmulo de biomassa provocada pelo efeito herbicida, foram classificados como altamente sensiveis a esse produto; aqueles com indice de intoxicação entre 11,17 e $27,00 \%$ e redução no acúmulo de biomassa foram classificados como medianamente sensiveis; e aqueles com menos de $11,17 \%$ de fitotoxicidade e sem perda de biomassa com a aplicação do Krismat ${ }^{\circledR}$ foram classificados como de baixa sensibilidade ao herbicida ou tolerantes.

\section{RESULTADOS E DISCUSSÃO}

Observou-se bom ajuste $(\mathrm{P}<0,001 \mathrm{e}$ $\mathrm{P}<0,005)$ entre a fitotoxicidade da mistura herbicida e dias após a aplicação dos tratamentos (DAT), representado por modelos polinomiais quadráticos (Figuras 1 a 3) no primeiro experimento.

O cultivar RB855113 e o clone RB957689 mostraram-se mais sensiveis à mistura herbicida no primeiro experimento, apresentando, respectivamente, índice de intoxicação (\% de fitotoxicidade) média de 13,75 e $15,00 \%$ aos 13 DAT, enquanto todos os demais cultivares apresentaram média de intoxicação inferior a 10,00\% (Figuras 1 a 3 e Tabela 1). Todavia, observando as curvas de evolução do índice de intoxicação de plantas por esse herbicida, verificou-se aumento acentuado dos sintomas

Planta Daninha, Viçosa-MG, v. 23, n. 1, p. 93-99, 2005 
para o cultivar RB855113, o qual se apresentou como o mais sensível, entre todos, à mistura herbicida.

Considerando o período entre 27 e 41 DAT, esses valores ficaram superiores a $40,00 \%$ (Figura 1), atingindo $44,40 \%$ aos 34 DAT (Tabela 1). Para os demais cultivares e clones, o maior índice de intoxicação, provocado pela mistura herbicida, ocorreu no período entre 27 e 34 DAT (Figuras 1 a 3 e Tabela 1). De todo o material testado, os cultivares SP80-1842, SP80-1816 e SP79-1011 e o clone RB957689 mostraram-se menos sensiveis à mistura herbicida, apresentando, respectivamente, valores de fitotoxicidade de 21,$16 ; 11,17$; 16,60; e 24,17\%, aos 34 DAT (Figuras 1 a 3 e Tabela 1). Quanto aos demais cultivares e clones avaliados (RB855002, RB928064, SP81-3250, RB867515, RB957712, RB72454, RB845210, RB947643, RB855536 e RB835486), eles apresentaram baixa sensibilidade à mistura, observando-se índice de intoxicação variando de 2,83 a 10,83\%, no período avaliado (Figuras 1 a 3 e Tabela 1). Rolin et al. (2001) observaram que o cultivar SP81-3250 apresentou sintomas visuais de fitotoxicidade à mistura thiazopir + ametryn. Tolerância diferenciada de cultivares de cana-de-açúcar foi também verificada por Velini et al. (2000). Esses autores, trabalhando com 10 cultivares

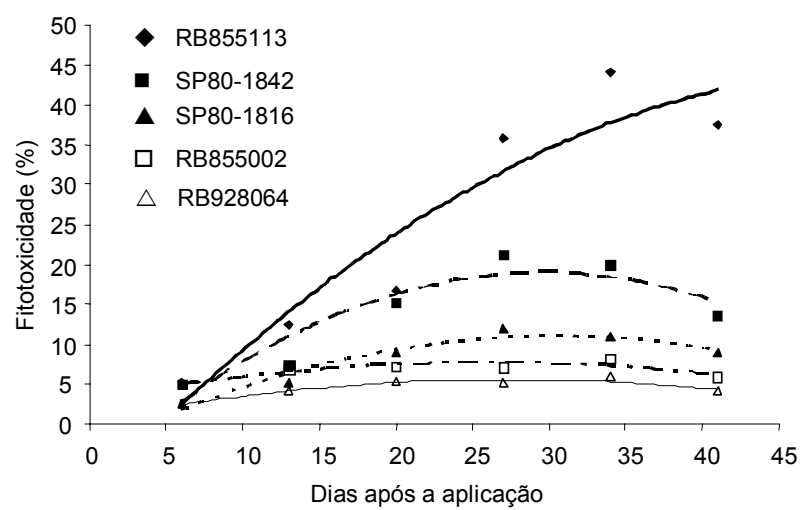

Figura 1 - Evolução da fitotoxicidade provocada pela mistura herbicida (trifloxysulfuron-sodium+ametryn) aplicada na dose de 2,00 $\mathrm{kg} \mathrm{ha}^{-1}$ do p.c. sobre os genótipos de cana-deaçúcar RB855113 ( $\hat{Y}=-0,0193 D^{2}+2,0326 D-9,0197$ $\left.\mathrm{R}^{2}=0,89\right), \operatorname{SP} 80-1842\left(\hat{\mathrm{Y}}=-0,0291 \mathrm{D}^{2}+1,7221 \mathrm{D}\right.$ $\left.-6,4738 ; \mathrm{R}^{2}=0,86\right), \operatorname{SP} 80-1816\left(\hat{\mathrm{Y}}=-0,0156 \mathrm{D}^{2}\right.$ $\left.+0,9473 \mathrm{D}-3,3271 ; \mathrm{R}^{2}=0,95\right), \operatorname{RB} 855002(\hat{\mathrm{Y}}=$ $\left.-0,0069 \mathrm{D}^{2}+0,3601 \mathrm{D}+3,1004 ; \mathrm{R}^{2}=0,77\right)$ e RB928064 $\left(\hat{\mathrm{Y}}=-0,0068 \mathrm{D}^{2}+0,3735 \mathrm{D}+0,4803, \mathrm{R}^{2}=0,93\right)$. de cana-de-açúcar submetidos à mistura de herbicidas oxyfluorfen + ametryn, constataram que o cultivar SP80-1842 apresentou alta sensibilidade a essa mistura, sendo observado índice de intoxicação da cultura superior a $44,00 \%$.

O índice de intoxicação da cana-de-açúcar pelo produto refletiu na produção de biomassa seca do material, sendo observada redução

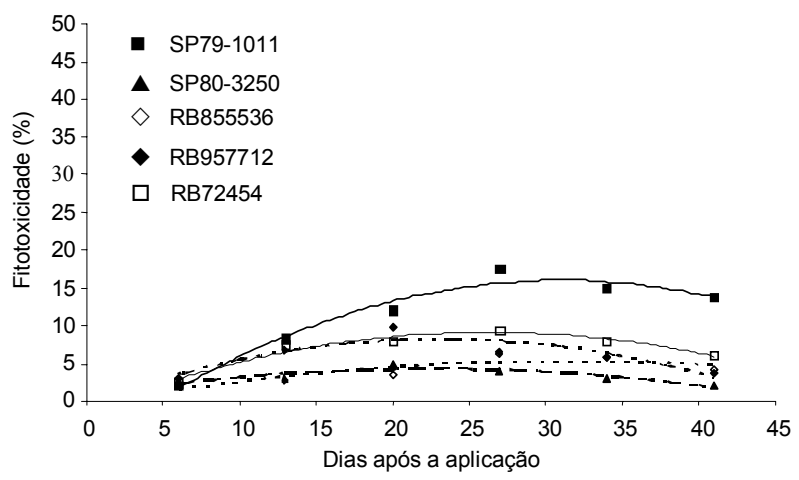

Figura 2 - Evolução da fitotoxicidade provocada pela mistura herbicida (trifloxysulfuron-sodium+ametryn) aplicada na dose de 2,00 kg ha-1 do p.c. sobre os genótipos de cana-deaçúcar SP79-1011 ( $\hat{Y}=-0,0228 D^{2}+1,415 \mathrm{D}-6,0118$; $\left.\mathrm{R}^{2}=0,96\right), \operatorname{SP} 81-3250\left(\hat{\mathrm{Y}}=-0,0071 \mathrm{D}^{2}+0,3197 \mathrm{D}\right.$ $\left.+0,6768 ; \mathrm{R}^{2}=0,81\right), \mathrm{RB} 867515\left(\hat{\mathrm{Y}}=-0,0058 \mathrm{D}^{2}\right.$ $\left.+0,3637 \mathrm{D}-0,4805 ; \mathrm{R}^{2}=0,74\right), \mathrm{RB} 957712(\hat{\mathrm{Y}}=$ $\left.-0,0159 \mathrm{D}^{2}+0,7392 \mathrm{D}-0,3699 ; \mathrm{R}^{2}=0,79\right)$ e $\mathrm{RB} 72454$ $\left(\hat{Y}=-0,0152 D^{2}+0,7996 D-1,3752 ; R^{2}=0,94\right)$.

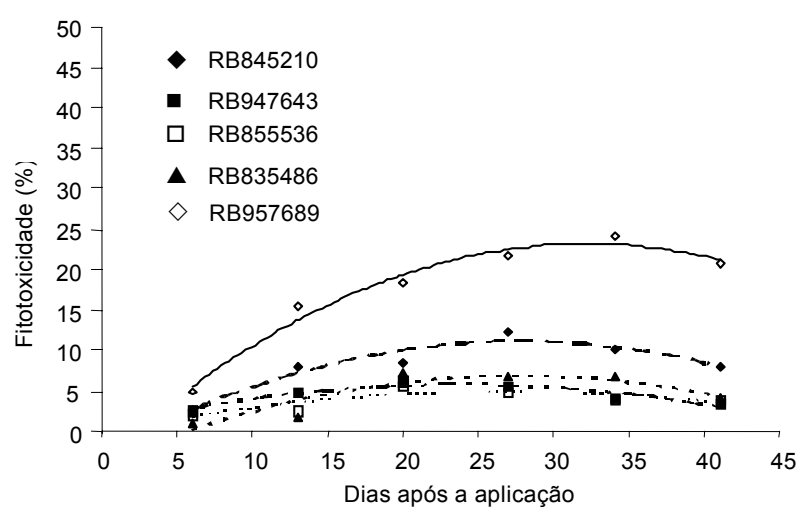

Figura 3 - Evolução da fitotoxicidade provocada pela mistura herbicida (trifloxysulfuron-sodium+ametryn) aplicada na dose de 2,00 $\mathrm{kg} \mathrm{ha}^{-1}$ do p.c. sobre os genótipos de cana-deaçúcar RB845210 ( $\hat{Y}=-0,0177 D^{2}+0,9872 D-2,645$; $\left.\mathrm{R}^{2}=0,90\right), \mathrm{RB} 947643\left(\hat{\mathrm{Y}}=-0,0097 \mathrm{D}^{2}+0,4608 \mathrm{D}\right.$ $\left.+0,3706 ; R^{2}=0,89\right), R B 855536\left(\hat{Y}=-0,0071 D^{2}+0,383 D\right.$ $\left.-0,3099 ; \mathrm{R}^{2}=0,71\right), \mathrm{RB} 835486\left(\hat{\mathrm{Y}}=-0,0143 \mathrm{D}^{2}\right.$ $\left.+0,7934 \mathrm{D}-4,1256 ; \mathrm{R}^{2}=0,81\right)$ e RB957689 ( $\hat{\mathrm{Y}}=$ $\left.-0,0256 \mathrm{D}^{2}+1,6496 \mathrm{D}-3,3914 ; \mathrm{R}^{2}=0,97\right)$. 
Tabela 1 - Efeito da mistura pré-formulada dos herbicidas trifloxysulfuron-sodium $\left(18,5 \mathrm{~g} \mathrm{~kg}^{-1}\right) \mathrm{mais}$ ametryn $\left(731,5 \mathrm{~g} \mathrm{~kg}^{-1}\right)$ aplicada na dose de $2,00 \mathrm{~kg} \mathrm{ha}^{-1}$ sobre 11 cultivares e quatro clones de cana-de-açúcar, para porcentagem de toxicidade visual, avaliada aos 13 e 34 dias após a aplicação dos tratamentos (DAT), e porcentagem relativa de produção de biomassa seca da parte aérea (BSPA), avaliada aos 45 DAT

\begin{tabular}{|c|c|c|c|c|}
\hline \multirow{2}{*}{ Clone } & \multicolumn{2}{|c|}{ Fitotoxicidade $(\%)^{*}$} & \multirow{2}{*}{$\operatorname{BSPA}(\%) *$} & \multirow{2}{*}{ Sensibilidade ao Krismat ${ }^{\circledR}$} \\
\hline & $13 \mathrm{DAT}$ & $34 \mathrm{DAT}$ & & \\
\hline RB855113 & $13,75 \mathrm{a}$ & $44,40 \mathrm{a}$ & $33,32 \mathrm{c}$ & alta \\
\hline SP80-1842 & $7,50 \mathrm{~b}$ & $21,16 \mathrm{~b}$ & $50,29 \mathrm{~b}$ & média \\
\hline SP80-1816 & $5,75 \mathrm{~b}$ & $13,17 \mathrm{c}$ & $58,73 \mathrm{~b}$ & média \\
\hline RB855002 & $6,25 \mathrm{~b}$ & $8,33 \mathrm{~d}$ & $94,79 \mathrm{a}$ & baixa \\
\hline RB928064 & $3,75 \mathrm{c}$ & $5,83 \mathrm{e}$ & $90,51 \mathrm{a}$ & baixa \\
\hline SP79-1011 & $8,50 \mathrm{~b}$ & $16,60 \mathrm{c}$ & $40,35 \mathrm{~b}$ & média \\
\hline SP81-3250 & $2,50 \mathrm{c}$ & $2,83 \mathrm{e}$ & $95,88 \mathrm{a}$ & baixa \\
\hline $\mathrm{RB} 867515$ & $4,25 \mathrm{c}$ & $5,83 \mathrm{e}$ & $94,45 a$ & baixa \\
\hline RB957712 & $2,50 \mathrm{c}$ & $6,33 \mathrm{e}$ & $88,53 a$ & baixa \\
\hline $\mathrm{RB} 72454$ & $7,50 \mathrm{~b}$ & $7,50 \mathrm{e}$ & $91,76 a$ & baixa \\
\hline $\mathrm{RB} 845210$ & $7,50 \mathrm{~b}$ & $10,83 \mathrm{~d}$ & $85,30 \mathrm{a}$ & baixa \\
\hline $\mathrm{RB} 947643$ & $5,00 \mathrm{~b}$ & $4,17 \mathrm{e}$ & $89,24 a$ & baixa \\
\hline $\mathrm{RB} 855536$ & $2,75 \mathrm{c}$ & $4,20 \mathrm{e}$ & $93,76 a$ & baixa \\
\hline RB835486 & $1,25 \mathrm{c}$ & $6,67 \mathrm{e}$ & $86,05 \mathrm{a}$ & baixa \\
\hline RB957689 & $15,00 \mathrm{a}$ & $24,17 \mathrm{~b}$ & $49,52 \mathrm{~b}$ & média \\
\hline
\end{tabular}

* Médias seguidas pela mesma letra em cada coluna não diferem entre si pelo critério de Scott Knott $(\mathrm{P}<0,05)$.

significativa para essa característica nos cultivares que apresentaram os maiores valores de porcentagem de toxicidade visual: RB855113, SP80-1842, SP80-1816, SP79-1011 e no clone RB957689 (Tabela 1). Foi observada no cultivar RB855113, que apresentou também alto indice de intoxicação, maior redução na produção de biomassa seca $(33,32 \%$ em relação à testemunha - Tabela 1). Os cultivares SP80-1842, SP80-1816 e SP79-1011 e o clone RB957689 mostraram redução menos acentuada de biomassa seca, produzindo, respectivamente, 50,29; 58,73; 40,35; e $49,52 \%$ em relação ao tratamento sem herbicida, porém sem diferirem significativamente (Tabela 1). Nos demais cultivares as reduções foram de no máximo $14,00 \%$, mas sob mesmo agrupamento pelo critério de Scott Knott (Tabela 1).

No segundo experimento foi observado bom ajuste $(\mathrm{P}<0,001$ e $\mathrm{P}<0,005)$ entre fitotoxicidade da mistura herbicida e doses do herbicida em kg ha-1, representado por modelos lineares e não-lineares. Neste experimento, constatou-se, para o cultivar RB855113, elevada sensibilidade à mistura herbicida, comparado com RB867515. Foi observada, no intervalo entre 20 e 27 DAT, semelhança no comportamento quanto à porcentagem de intoxicação, para os dois cultivares (Figuras 4 e 5).

No cultivar RB855113 observou-se, entre 20 e 27 DAT, intoxicação em todas as doses

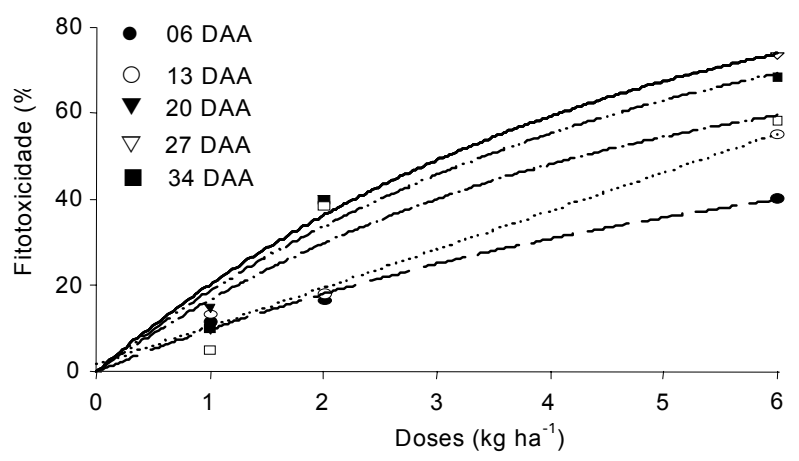

Figura 4 - Evolução da fitotoxicidade provocada pela mistura herbicida (trifloxysulfuron-sodium+ametryn) aplicada no cultivar RB855113 aos $6\left(62,1101\left[1-\mathrm{e}^{(-0,1711 \mathrm{D})}\right], \mathrm{R}^{2}=0,99\right)$, $13\left(1,6064+8,9157 \mathrm{D}, \mathrm{R}^{2}=0,99\right), 20\left(99,0594\left[1-\mathrm{e}^{(-0,2276 \mathrm{D})}\right]\right.$, $\left.\mathrm{R}^{2}=0,98\right), 27\left(99,0599\left[1-\mathrm{e}^{(-0,2250 \mathrm{D})}\right], \mathrm{R}^{2}=0,98\right)$, $34\left(93,7516\left[1-\mathrm{e}^{(-0,2224 \mathrm{D})}\right], \mathrm{R}^{2}=0,94\right)$ e 41 DAT $(77,5901$ $\left.\left(1-\mathrm{e}^{(-0,2415 \mathrm{D})}\right], \mathrm{R}^{2}=0,85\right)$.

Planta Daninha, Viçosa-MG, v. 23, n. 1, p. 93-99, 2005 
testadas da mistura herbicida, com redução de $20,00 \%$ na menor dose, $40,00 \%$ na dose recomendada e mais de $70,00 \%$ na maior dose (Figura 4). Aos 34 e 41 DAT foi observado índice de intoxicação de 69,04 e 59,37\%, respectivamente, para a maior dose desse mesmo cultivar (Figura 4).

No cultivar RB867515, a maior toxicidade foi observada aos 34 DAT; no entanto, esse valor foi inferior a $10,00 \%$ na dose recomendada e em torno de $16,00 \%$ na maior dose testada (Figura 5), confirmando boa tolerância desse material à mistura herbicida.

Estudos com herbicidas de ação localizada indicam que a cultura da cana-de-açúcar pode tolerar até $27,00 \%$ de comprometimento de sua área foliar sem que isso implique redução da produtividade (Veline et al., 1993). Entretanto, para herbicidas sistêmicos esses valores podem ser diferentes, dependendo do processo fisiológico afetado pelo produto. Azania et al. (2001), trabalhando com os herbicidas imazapyr e tebuthiuron aplicados no cultivar RB835089, constataram leve intoxicação na fase inicial do desenvolvimento e total recuperação da cultura aos 100 DAT, sem prejuizo para produtividade e qualidade da matéria-prima.

Para as características altura de plantas, área foliar, número de folhas e biomassas secas foliar e caulinar, em função das doses

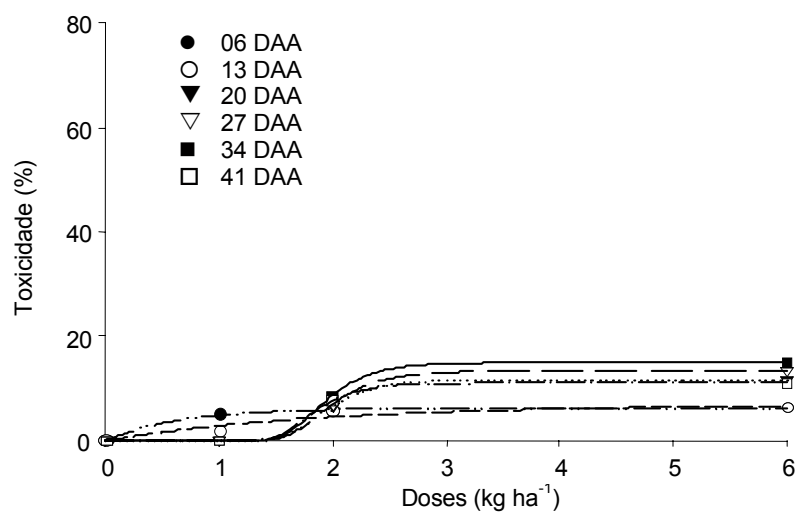

Figura 5 - Evolução da fitotoxicidade provocada pela mistura herbicida (trifloxysulfuron-sodium+ametryn) aplicada no cultivar RB867515 aos $6\left(6,1787\left[1-\mathrm{e}^{(-0,5737 \mathrm{D})}\right], \mathrm{R}^{2}=\right.$ $0,99), 13\left(6,84\left[1-\mathrm{e}^{(-0,5455 \mathrm{D})}\right], \mathrm{R}^{2}=0,84\right), 20(11,67$ $\left.\left[1-\mathrm{e}^{-3,5596 \mathrm{D}}\right]^{691,1016}, \mathrm{R}^{2}=0,99\right), 27\left(13,33\left[1-\mathrm{e}^{-3,4487 \mathrm{D}}\right]^{637,381}\right.$, $\left.\mathrm{R}^{2}=0,99\right), 34\left(15\left[1-\mathrm{e}^{-3,605 \mathrm{D}}\right]^{741,8032}, \mathrm{R}^{2}=0,99\right)$ e 41 DAT $\left(11\left[1-\mathrm{e}^{-4,0399}\right]^{1165,3321}, \mathrm{R}^{2}=0,99\right)$.

Planta Daninha, Viçosa-MG, v. 23, n. 1, p. 93-99, 2005

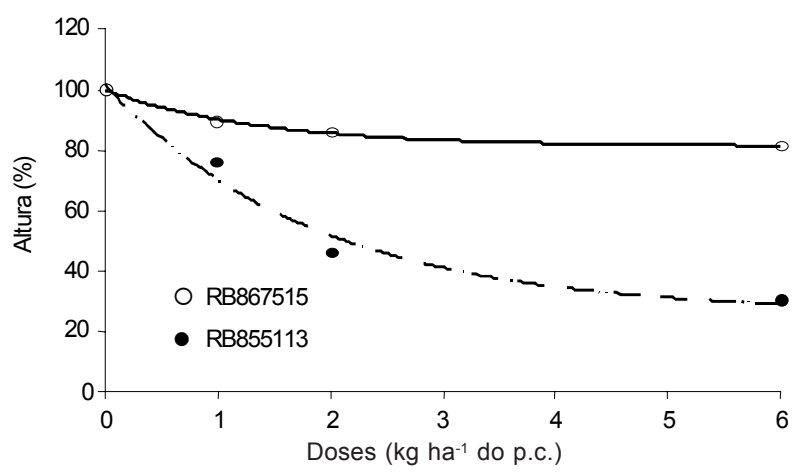

Figura 6 - Porcentagem de altura de plantas dos cultivares $\operatorname{RB} 867515\left(\hat{\mathrm{Y}}=81,4027+18,4967 \mathrm{e}^{(-0,7375 \mathrm{D})}, \mathrm{R}^{2}=0,99\right) \mathrm{e}$ $\operatorname{RB} 855113\left(\hat{\mathrm{Y}}=26,3487+75,355 \mathrm{e}^{(-0,5404 \mathrm{D})}, \mathrm{R}^{2}=0,92\right)$ após aplicação da mistura herbicida (trifloxysulfuronsodium+ametryn).

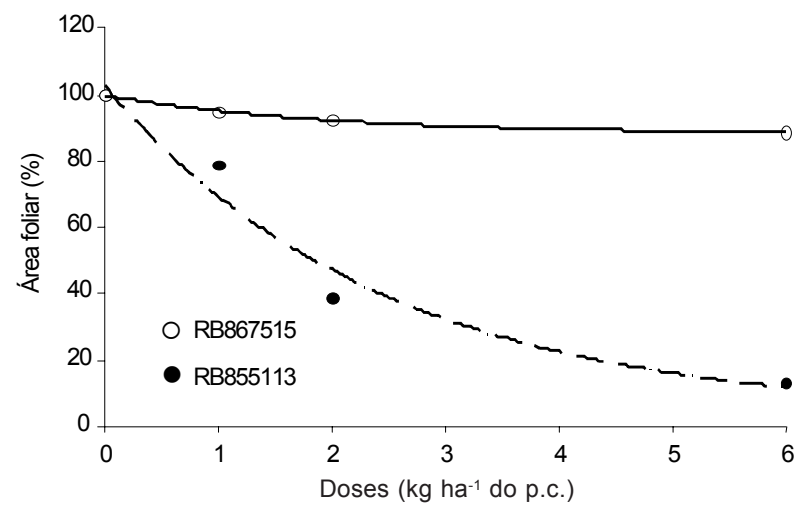

Figura 7 - Porcentagem de área foliar de plantas dos cultivares $\operatorname{RB} 867515\left(\hat{\mathrm{Y}}=88,29+11,6652 \mathrm{e}^{(-0,5145 \mathrm{D})}, \mathrm{R}^{2}=0,99\right) \mathrm{e}$ $\operatorname{RB} 855113\left(\hat{\mathrm{Y}}=3,4736+99,4933 \mathrm{e}^{(-0,4107 \mathrm{D})}, \mathrm{R}^{2}=0,89\right)$ após aplicação da mistura herbicida (trifloxysulfuronsodium+ametryn).

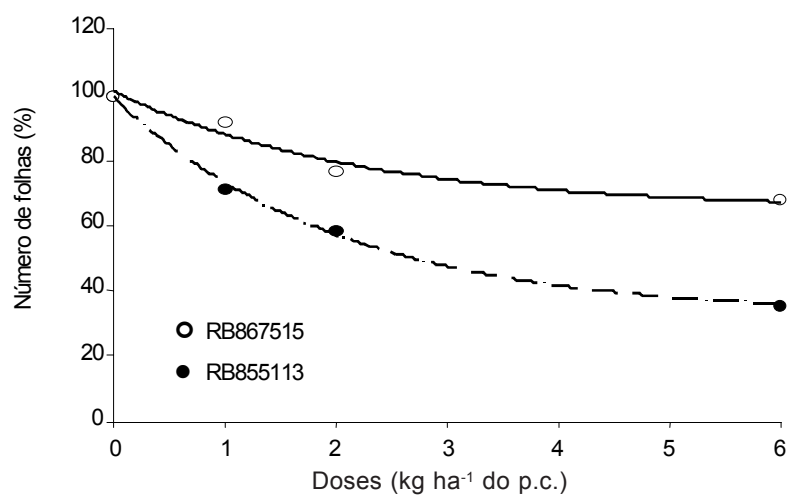

Figura 8 - Porcentagem de número de folhas de plantas dos cultivares RB867515 ( $\hat{\mathrm{Y}}=64,9588+36,1086 \mathrm{e}^{(-0,4534 \mathrm{D})}$, $\left.\mathrm{R}^{2}=0,88\right)$ e $\mathrm{RB} 855113\left(\hat{\mathrm{Y}}=32,7101+66,7750 \mathrm{e}^{(-0,4994 \mathrm{D})}\right.$, $\left.\mathrm{R}^{2}=0,99\right)$ após aplicação da mistura herbicida (trifloxysulfuron-sodium+ametryn). 


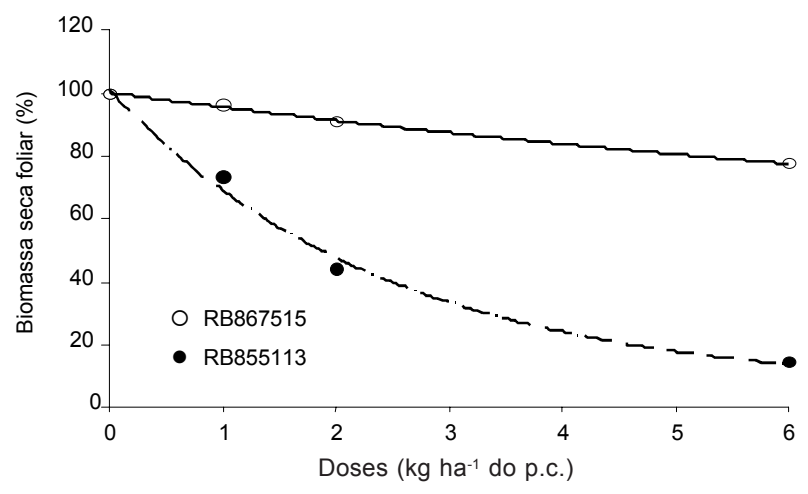

Figura 9 - Porcentagem de biomassa seca das folhas dos cultivares RB867515 ( $\hat{\mathrm{Y}}=41,4843+58,7085 \mathrm{e}^{(-0,0810 \mathrm{D})}$, $\left.\mathrm{R}^{2}=0,99\right)$ e $\mathrm{RB} 855113\left(\hat{\mathrm{Y}}=5,5339+95,7383 \mathrm{e}^{(-0,41102 \mathrm{D})}\right.$, $\left.\mathrm{R}^{2}=0,98\right)$ após aplicação da mistura herbicida (trifloxysulfuron-sodium+ametryn).

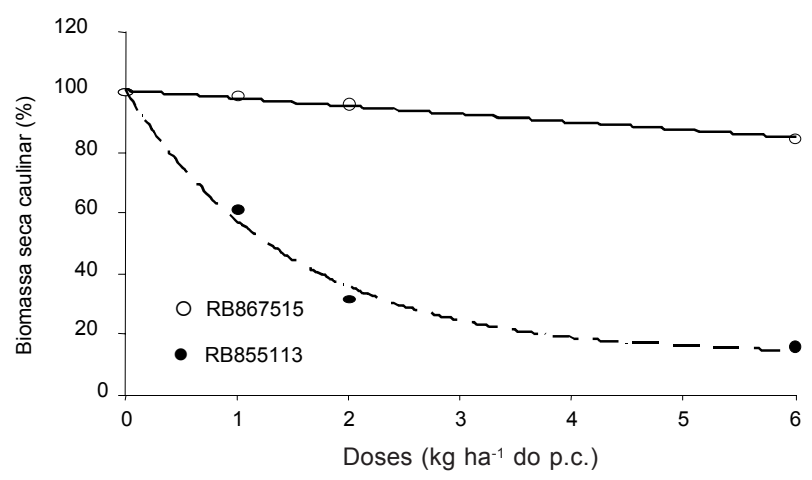

Figura 10 - Porcentagem de biomassa seca do caule dos cultivares RB867515 ( $\hat{\mathrm{Y}}=-786,4081+887,2092 \mathrm{e}^{(-0,0030 \mathrm{D})}$, $\left.\mathrm{R}^{2}=0,97\right)$ e $\mathrm{RB} 867515$ ( $\hat{\mathrm{Y}}=13,2198+87,7467 \mathrm{e}^{(-0,6790 \mathrm{D})}$, $\left.\mathrm{R}^{2}=0,97\right)$ após aplicação da mistura herbicida (trifloxysulfuron-sodium+ametryn).

da mistura herbicida, foram ajustados modelos não-lineares para os cultivares RB855113 e RB867515 (Figuras 6 a 10).

O cultivar RB855113 apresentou tendência de redução na altura de planta, na área foliar, no número de folhas e nas biomassas secas foliar e caulinar com o aumento da dose, chegando, respectivamente, a 30,54\%, 13,34\%, $36,00 \%, 14,30 \%$ e $15,85 \%$ na maior dose. Por outro lado, em RB867515 essa tendência de redução foi menor, porém com redução significativa nas características avaliadas (Figuras 6 a 10).

Portanto, pode-se afirmar que os cultivares apresentam sensibilidade diferencial à mistura herbicida, sendo RB855113 o mais sensivel ao herbicida mesmo nas doses mais baixas. Os cultivares SP80-1842, SP80-1816, SP79-1011 e RB957689 apresentaram média sensibilidade à mistura de herbicidas. Nos demais cultivares essa sensibilidade foi considerada baixa.

\section{LITERATURA CITADA}

AZANIA, C. A. M. et al. Seletividade de imazapic às soqueiras de cana-de-açúcar (Saccharum spp.). Planta Daninha, v. 19, n. 3, p. 345-350, 2001.

COMISSÃO DE FERTILIDADE DO SOLO DO ESTADO DE MINAS GERAIS - CFSEMG. Recomendações para o uso de corretivos e fertilizantes em Minas Gerais - $5^{\text {a }}$ aproximação. Viçosa-MG: Universidade Federal de Viçosa, 1999. $359 \mathrm{p}$.

CONSTANTIN, J. Avaliação da seletividade do herbicida halosulfuron à cana-de-açúcar. 1997. $71 \mathrm{f}$. Dissertação (Mestrado em Agronomia) - Universidade Estadual de São Paulo, Botucatu, 1997.

PROCÓPIO, S. O. et al. Manejo de plantas daninhas na cultura da cana-de-açúcar. Viçosa-MG: Universidade Federal de Viçosa, 2003. 150 p.

ROLIM, J. C. et al. Tolerância de cana-de-açúcar à aplicação seqüencial de nematicidas e herbicidas. R. Bras.

Herbicidas, v. 2, n. 3, p. 113-117, 2001.

SANTOS, J. B. et al. Seletividade do herbicida trifloxysulfuron sodium para fins de fitorremediação.

R. Ceres, v. 51, n. 293, p. 129-141, 2004.

SCHUMM, K. C.; BRAZ, B. A. Comportamento do trifloxysulfuron sodium + ametrina + MSMA no controle de plantas daninhas e intoxicação às plantas de cana-de-açúcar (Saccharum ssp.). In: CONGRESSO BRASILEIRO DA CIÊNCIA DAS PLANTAS DANINHAS. Resumos... Gramado - RS: SBCPD, 2002. p. 502.

SILVA, A. A. et al. Controle de plantas daninhas. Brasília: ABEAS, 2003. p. 260.

VELINI, E. D. et al. Avaliação da seletividade da mistura de oxyfluorfen e ametryne, aplicada em pré e pós-emergência, a dez variedades de cana-de-açúcar (cana planta). Planta Daninha, v. 18, n. 2, p. 123-134, 2000.

VELINI, E. D. et al. Avaliação dos efeitos do herbicida clomazone, aplicado em pós-emergência, sobre o crescimento e produtividade de soqueiras de nove cultivares de cana-deaçúcar. In: CONGRESSO NACIONAL DA SOCIEDADE DOS TÉCNICOS AÇUCAREIROS E ALCOOLEIROS DO BRASIL - STAB, 5., 1993, Águas de São Pedro. Anais... Águas de São Pedro: STAB, 1993. p. 125-128.

WIXSON, M. B. et al. Use of AC 263,222 for sicklepod (Cassia obtusifolia) control in soybean (Glycine max). Weed Technol., v. 5, p. 276-279, 1991.

Planta Daninha, Viçosa-MG, v. 23, n. 1, p. 93-99, 2005 